1 Thompson AE. 'You are instructed to prepare a report ... ': How to make sound decisions about whether to accept or decline medico-legal work. Psychiatrist 2011; 35: 269-72.

2 Rix KJB. Medico-legal work of psychiatrists: direction, not drift. Commentary on ... 'You are instructed to prepare a report'. Psychiatrist 2011; 35: 272-4.

3 Jones v. Kaney [2011] UKSC 13.

Philip Steadman, Consultant Psychiatrist, Oxleas NHS Foundation Trust, UK, email: Phil.Steadman@oxleas.nhs.uk

doi: 10.1192/pb.35.11.430a

\section{The psychiatrist as expert witness}

Thompson $^{1}$ and Rix ${ }^{2}$ make particularly interesting statements regarding continuing professional education in the area of providing expert reports. I generally agree with the requirements listed by Thompson, with the exception of expecting the psychiatrist to have had specific training in being an expert witness. It seems to me that, although advice about conduct in court is prudent, the requirement of specific training is redundant. The competence and expertise of the witness should rapidly become apparent to the court during the process of giving evidence and being cross-examined.

The testing of a witness's competence is strictly a matter for the court. Indeed, one of the attractions of my medico-legal work over the past 40 years has been that my knowledge and competence are examined in a very rigorous manner by counsel in the course of giving evidence. I would be concerned if our own professional body were to suggest that an answer in court that one had met the accepted requirements of training as a witness were to replace this.

If the courts were to need such support from our College, it would imply that the general level of competence at the Bar is insufficient and our colleagues at the Inns of Court may need to reconsider their training. For ourselves, our expertise resides in psychiatry with an understanding of the law, not being experts at the law.

1 Thompson AE. 'You are instructed to prepare a report ... ': How to make sound decisions about whether to accept or decline medico-legal work. Psychiatrist 2011; 35: 269-72.

2 Rix KJB. Medico-legal work of psychiatrists: direction, not drift. Commentary on ... 'You are instructed to prepare a report'. Psychiatrist 2011; 35: 272-4.

Gordon R. W. Davies, Psychiatrist, University of Wollongong, New South Wales, Australia, email: alienist@ihug.com.au

doi: $10.1192 / \mathrm{pb} .35 .11 .431$

\section{Psychiatric reports: a must for all psychiatrists}

Thompson's article ${ }^{1}$ about preparing psychiatric reports for courts contains some useful advice, but we were left wondering why she had taken the time to write it, given that she suggests such reticence in taking on this work.

Criminal and other courts rely on psychiatric evidence on occasion and, at least in the UK jurisdiction, where dual loyalties to the court and to the patient are tolerated, ${ }^{2}$ a report for a criminal court is often best prepared by the psychiatrist who knows the patient and will be treating them. Sometimes, for that very reason, a psychiatrist will prefer not to be involved in a court case, but equally, there are cases where they really should be involved, because they will be carrying out the treatment that sentencing might support or enable.

It may be better for a consultant who does not do such work regularly to seek supervision from a more experienced colleague, rather than simply refuse to provide it, as Thompson suggests. There are many other situations in which courts need expert psychiatric evidence, either to meet statutory requirements or on higher court guidance. It is essential that there is a body of psychiatrists available that is willing and able to provide this, and there is no reason why it should come, as Thompson implies, exclusively from the ranks of forensic psychiatrists or clinicians who do not work for the NHS.

Training then becomes crucial, and Rix $^{3}$ has - much more encouragingly - discussed some of the ways in which it can be acquired. However, he does not address some of the associated matters that Thompson rightly raises. In particular, matters of probity relating to payment for work done and the interface between providing fee-paying services (category 2 work, as it was) and one's contractual NHS duties are important, and perhaps are not given the explicit attention in training and supervision that they deserve.

In the West Midlands we have prepared explicit guidelines for forensic trainees who are required to engage in this work. This covers matters such as the requirements for supervision and how best to acknowledge this within the report, the arrangements agreed with local employing trusts in relation to office support, guidance on providing estimates of costs and on what aspects of the work are chargeable, the requirements of Part 33 of the Criminal Procedure Rules 2010, and issues of consent, confidentiality and information governance. Although some of these matters are complex and may encompass some variety of practice, the principles are generally clear enough and need to be established openly.

In particular, when preparing a court report, a series of aims or outcomes may be conflated, including the (in category 2 terms) primary outcome of assisting a third party (the court) to meet its objectives (by dealing with the case justly), but also including preparing for the assessment and treatment of the patient in hospital (category 1 work as was), and personal learning and development for the clinician. The amount of time charged for should properly reflect this. Dealing with money may be sensitive, but a trainee's court report work must be explicitly supervised in terms of probity as well as clinical quality.

We agree with Rix that it would be a shame if psychiatrists were put off gaining competencies in this potentially rewarding, but also necessary, area of work. Many of Thompson's concerns can be successfully addressed by a more open attitude to the complex probity issues that are involved, rather than simply deciding 'not to undertake this work at all'.

\section{Declaration interest}

Both authors have provided expert reports for the courts in criminal proceedings of varying degrees of seriousness and complexity.

1 Thompson AE 'You are instructed to prepare a report ...' How to make sound decisions about whether to accept or decline medico-legal work. Psychiatrist 2011; 35: 269-72. 